\title{
PENGGUNAAN FITOHORMON EKSTRAK BAWANG MERAH (Allium cepa L.) UNTUK PERTUMBUHAN MATERI SETEK BATANG PANGKAL, TENGAH, DAN PUCUK TANAMAN MURBEI (Morus multicaulis)
}

(The Use of Fitohormon Extract of Shallot (Allium cepa L.) For the Growth of Plant Material in the Base, Middle, and Mulberry Shoots (Morus multicaulis))

\author{
Nengsih, Abdurrani Muin, Iskandar \\ Fakultas Kehutanan Universitas Tanjungpura J1. Daya Nasional Pontianak 78124 \\ Email: nengsih932@gmail.com
}

\begin{abstract}
The research aim to determine the effect of the use of phytohormone extracts of red onion (Allium cepa), stem cuttings material and the interaction of phytohormone extracts of A. cepa with stem cuttings material on the growth of mulberry (Morus multicaulis) plants. This research was conducted at the Research and Development Institute of Tanjungpura University from March to May 2019. The method of research was an experimental method with a Split Plot Design. The treatments consisted of the stem cutting materials (base, middle and shoot) as the main plot and the dose of shallots extract $(0 \mathrm{~g} / \mathrm{l}, 500 \mathrm{~g} / \mathrm{l}$ and $1000 \mathrm{~g} / \mathrm{l})$ as subplots. Each treatment consisted of three groups, so that the total of treatments were 27 plots. The results showed that only the dose of shallots extract which significant influented on the M. multicaulis growth. Whereas the stem cutting materials and interactionsof both were did not effect significantly. The highest of murbei growth was obtained at $1000 \mathrm{~g} / \mathrm{l}$ of shallot extract on $6,52 \%$ of the leaves number, $500 \mathrm{~g} / \mathrm{l}$ of branch length $4,52 \%$ and $3.88 \%$ of the roots number. Thus, the extract of A. cepa $L$ can be used as an alternative for plant growth, especially M. multultulis plants.
\end{abstract}

Keywords: Mulberry, stem cuttings, phytohormone.

\section{PENDAHULUAN}

Berdasarkan Peraturan Menteri

Kehutanan, No.P.35/Menhut-II/2007 mengenai HHBK, tanaman murbei termasuk salah satu dari hasil hutan bukan kayu (HHBK). Tanaman murbei (Morus multicaulis) memiliki potensi yang dapat ditingkatkan nilai kegunaaannya terutama sebagai pakan ulat sutra. Hasil dari budidaya ulat sutra berupa kokon dapat diolah menjadi benang sutra sebagai bahan untuk pembuatan kain sutera. Kokon juga bisa langsung dipasarkan tanpa melakukan pengolahan. Selain itu tanaman murbei juga memiliki banyak manfaat lain seperti bahan pangan, obat-obatan dan konservasi (Isnan dan Muin, 2015).

Tanaman murbei yang terdapat di Indonesia, umumnya dikembangkan dan dibudidayakan secara vegetatif melalui setek batang. Setek yang digunakan terdiri dari tiga bagian yaitu bagian pangkal, tengah dan pucuk. Permasalahannya dari tiga bagian itu mana yang terbaik untuk pertumbuhan setek murbei. Selain itu untuk mempercepat pertumbuhan setek murbei, dibutuhkan fitohormon dan dalam penelitian ini menggunakan bawang merah (Allium cepa). Namun bagian batang mana yang terbaik dan 
berapa dosis fitohormon A. cepa yang harus digunakan untuk pertumbuhan murbei tersebut. Berdasarkan kedua permasalahan tersebut maka, perlu dilakukan penelitian mengenai penggunaan fitohormon $A$. серa untuk pertumbuhan materi setek batang pangkal, tengah dan pucuk tanaman murbei.

Tujuan penelitian adalah menentukan kemungkinan penggunaan fitohormon A. cepa, bagian batang bawah tengah atau atas yang terbaik untuk pertumbuhan setek batang dan interaksi antara zat pengatur tumbuh dengan bagian setek batang. Hasil penelitian ini dapat digunakan sebagai acuan materi setek batang yang terbaik untuk petumbuhan setek murbei $(M$. multicaulis) dengan menggunakan fitohormon A. cepa.

\section{METODE PENELITIAN}

Penelitian dilaksanakan di Lembaga Penelitian dan Pengembangan Universitas Tanjungpura Pontianak selama 2 bulan. Jenis penelitian berdasarkan metode eksperimen yang menggunakan Acak Petak Terpisah (Split Plot Design) dengan pola dasar Rancangan Acak Kelompok (RAK), dengan perlakuan sebagai berikut.

1) Sebagai petak utama (mainplot) adalah materi batang setek yang terdiri dari batang bagian pangkal, tengah dan pucuk.
2) Sebagai anak petak (subplot) adalah konsentrasi fitohormon $A$. сера sebanyak $0 \mathrm{~g} / \mathrm{l}\left(\mathrm{Z}_{0}\right), 500 \mathrm{~g} / \mathrm{l}\left(\mathrm{Z}_{1}\right)$, dan $1000 \mathrm{~g} / \mathrm{l}\left(\mathrm{Z}_{2}\right)$.

Penelitian ini terdiri dari 3 kelompok yaitu berupa setek yang diambil pada 3 cabang tanaman murbei, sehingga menggunakan $3 \times 3 \times 3=27$ plot. Data utama dalam penelitian adalah jumlah tunas, jumlah daun, panjang cabang, jumlah akar dan jumlah tanaman yang hidup. Selain itu, data pendukung meliputi pengukuran suhu udara, kelembaban udara dan pemeliharaan seperti penyiraman 2 kali sehari dan penyiangan gulma disekitar tanaman.

\section{HASIL DAN PEMBAHASAN Jumlah Tunas}

Hasil pengukuran terhadap jumlah tunas yang disajikan pada Tabel 1 menunjukkan bahwa perlakuan materi batang memiliki jumlah tunas yang hampir sama. Demikian juga untuk perlakuan penggunaan fitohormon $A$. cepa dengan dosis $0 \mathrm{~g} / 1$ sampai $1000 \mathrm{~g} / \mathrm{l}$ menunjukkan jumlah yang hampir sama. Sementara itu, dari interaksi kedua perlakuan tersebut, ternyata kombinasi materi batang pucuk tanpa fitohormon A. cepa lebih baik (rata-rata 4,00 tunas) dibandingkan kombinasi perlakuan lainnya. 
Tabel 1. Hasil pengukuran jumlah tunas menggunakan perlakuan materi setek batang dan fitohormon $A$. cepa (The results of the measurement of the number of shoots using material treatment of stem cuttings and fitohormon A. cepa)

\begin{tabular}{cccccc}
\hline Materi Setek & \multicolumn{3}{c}{ Fitohormon A. cepa } & \multirow{2}{*}{ Total } & Rerata \\
\cline { 2 - 4 } Batang & $\mathrm{Z}_{0}$ & $\mathrm{Z}_{1}$ & $\mathrm{Z}_{2}$ & & 4.00 \\
\hline Pangkal & 6 & 4 & 2 & 12 & 3.00 \\
Tengah & 3 & 2 & 4 & 9 & 3.33 \\
Pucuk & 2 & 3 & 5 & 10 & 10.33 \\
\hline Total & 11 & 9 & 11 & 31 & 3.44 \\
\hline Rerata & 3.67 & 3.00 & 3.67 & 10.33 & \\
\hline
\end{tabular}

$$
\text { Keterangan : } \begin{aligned}
\mathrm{Z}_{0} & =\text { Kontrol }(0 \mathrm{~g} / \mathrm{l}) \\
\mathrm{Z}_{1} & =\text { Fitohormon } A \text {. cepa } 500 \mathrm{~g} / \mathrm{l} \\
\mathrm{Z}_{2} & =\text { Fitohormon } A \text {. cepa } 1000 \mathrm{~g} / \mathrm{l}
\end{aligned}
$$

Berdasarkan hasil analisis keragaman, ternyata perlakuan materi setek batang yang dikombinasikan dengan fitohormon A. cepa tidak menunjukkan pengaruh yang nyata terhadap jumlah tunas. Ini berarti bahwa pembuatan setek batang murbei dapat menggunakan materi setek pangkal, tengah dan pucuk. Hal ini diduga karena pengaruh hormon auksin yang terdapat dalam materi setek batang yang tidak berbeda, meskipun, menurut Ramadan et al. (2016) auksin paling banyak terdapat dibagian pangkal (bawah) tanaman dan semakin jauh dari ujung tanaman, maka kandungan auksin semakin sedikit. Hasil penelitian juga menunjukkan bahwa $A$. серa sebagai fitohormon juga belum dapat meningkatkan pertumbuhan tunas. Hal ini diduga waktu perendaman selama 12 jam belum dapat menyerap fitohormon dari A. cepa yang dijadikan sebagai fitohormon. Selain itu, ukuran diameter setek batang yang digunakan lebih dari $1 \mathrm{~cm}(1,65 \mathrm{~cm})$ membutuhkan waktu perendaman yang lebih lama. Berbeda dengan penelitian tanaman melati putih yang dilakukan oleh Lesmana et al (2018) dengan diameter yang kurang dari $0,5 \mathrm{~cm}$.

\section{Jumlah Daun}

Berdasarkan Tabel 2 ternyata perlakuan materi setek batang menunjukkan pertumbuhan jumlah daun yang hampir sama. Perlakuan penggunaan fitohormon A. cepa dengan dosis $1000 \mathrm{~g} / \mathrm{l}$ menunjukkan jumlah daun yang lebih banyak dibandingkan dengan $0 \mathrm{~g} / \mathrm{l}$ dan $500 \mathrm{~g} / \mathrm{l}$. Sementara itu, untuk interaksi kedua perlakuan terlihat bahwa jumlah daun dengan perlakuan materi setek tengah dan pucuk yang diberi fitohormon sebanyak $1000 \mathrm{~g} / \mathrm{l}$ lebih banyak dibandingkan dengan kombinasi perlakuan lainnya. 
Tabel 2. Hasil pengukuran jumlah daun menggunakan perlakuan materi setek batang dan fitohormon $A$. cepa (The results of the measurement of the number of leaves using the material treatment of stem cuttings and fitohormon A. cepa)

\begin{tabular}{cccccc}
\hline \multirow{2}{*}{ Materi Setek Batang } & \multicolumn{3}{c}{ Fitohormon A. cepa } & \multirow{2}{*}{ Total } & \multirow{2}{*}{ Rerata } \\
\cline { 2 - 4 } & $\mathrm{Z}_{0}$ & $\mathrm{Z}_{1}$ & $\mathrm{Z}_{2}$ & & \\
\hline Pangkal & 19 & 17 & 10 & 46 & 15.33 \\
Tengah & 7 & 18 & 20 & 45 & 15.00 \\
Pucuk & 6 & 13 & 24 & 43 & 14.33 \\
\hline Total & 32 & 48 & 54 & 134 & 44.67 \\
\hline Rerata & 10.67 & 16.00 & 18.00 & 44.67 & 14.89 \\
\hline
\end{tabular}

Keterangan : $Z_{0}=$ Kontrol $(0 \mathrm{~g} / \mathrm{l})$

$\mathrm{Z}_{1}=$ Fitohormon A. cepa $500 \mathrm{~g} / 1$

$\mathrm{Z}_{2}=$ Fitohormon $A$. cepa $1000 \mathrm{~g} / \mathrm{l}$

Berdasarkan hasil analisis menunjukkan pengaruh yang nyata keragaman, ternyata perlakuan materi terhadap jumlah daun terlihat pada setek batang yang dikombinasikan Tabel 3 berikut.

dengan fitohormon $A$. cepa

Tabel 3. Hasil analisis keragaman pengaruh perlakuan materi setek batang dan fitohormon $A$. cepa terhadap jumlah daun (The results of the analysis of the diversity of the effect of stem cuttings and phytohormone A. cepa treatment on the number of leaves)

\begin{tabular}{ccccccc}
\hline $\begin{array}{c}\text { Sumber } \\
\text { keragaman }\end{array}$ & DB & JK & KT & F-hitung & \multicolumn{2}{c}{ F-tabel } \\
\cline { 6 - 7 } $\begin{array}{c}\text { Petak utama } \\
\text { Kelompok }\end{array}$ & 2 & 1,12 & 0,56 & $0,46^{\text {tn }}$ & & $1 \%$ \\
$\begin{array}{c}\text { Materi setek } \\
\text { batang }\end{array}$ & 2 & 0,01 & 0,01 & $0,00^{\text {tn }}$ & 6,94 & 18 \\
Galat a & 4 & 4,87 & 1,22 & & & \\
\hline Subplot & & & & & & \\
A. cepa & 2 & 7,96 & 3,98 & $6,52^{*}$ & 3,88 & 6,93 \\
Interaksi & 4 & 4,3 & 1,08 & $1,76^{\text {tn }}$ & 3,26 & 5,41 \\
Galat b & 12 & 7,32 & 0,61 & & & \\
\hline Total & \multicolumn{7}{c}{ kk a $=29,98 \%$ dan $\mathrm{kk} \mathrm{b}=21,22 \%$} \\
\hline
\end{tabular}

Keterangan :

tn $=$ tidak nyataGalat

$\mathrm{b}=$ perlakuan $A$. cepa

* = berpengaruh nyatakk

$\mathrm{a}=$ koefisien keragaman materi setek batang

Galat

$\mathrm{a}=$ perlakuan materi setek batangkk

$\mathrm{b}=$ koefisien keragaman $A$. серa 
Hasil Uji Beda Jujur, ternyata penggunaan $A$. cepa sebagai fitohormon sebanyak 500g/l dan $1000 \mathrm{~g} / 1$ berbeda nyata dengan tanpa fitohormon A. cepa. Sementara, perlakuan A. cepa sebanyak $500 \mathrm{~g} / \mathrm{l}$ tidak berbeda nyata dengan pemberian sebanyak $1000 \mathrm{~g} / \mathrm{l}$. Hasil penelitian ini menunjukkan bahwa penggunaan $A$. cepa sebagai fitohormon sebanyak 500g/l sudah cukup untuk meningkatkan pertumbuhan daun murbei. Hal ini sesuai hasil penelitian Lesmana et al (2018) dalam hal pengaruh berbagai zat pengatur tumbuh bawang merah dan asal setek terhadap
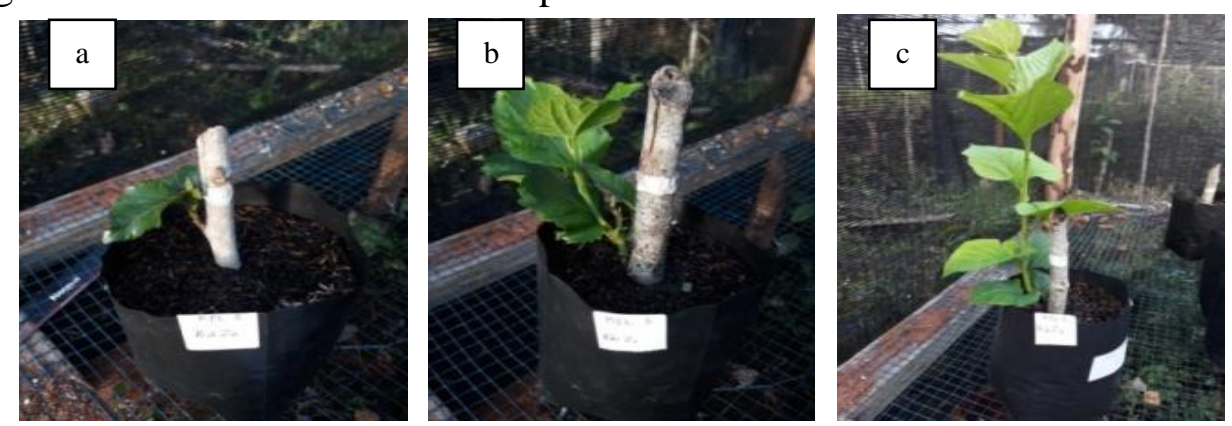

Gambar 1. Jumlah daun menggunakan perlakuan fitohormon A. cepa (a) tanpa perlakuan (0 g/l), (b) dosis $500 \mathrm{~g} / \mathrm{l}$, (c) dosis $1000 \mathrm{~g} / \mathrm{l}$ (Number of leaves using phytohormone A. cepa treatment (a) without treatment $(0 \mathrm{~g} / \mathrm{l})$, (b) dose $500 \mathrm{~g} / \mathrm{l}$, (c) dose $1000 \mathrm{~g} / \mathrm{l})$.

\section{Panjang Cabang}

Hasil pengukuran panjang cabang yang dikemukakan pada Tabel 4 menunjukan bahwa perlakuan materi setek batang tengah dan pucuk memiliki cabang tunas yang lebih panjang dibandingkan bagian pangkal. Sementara itu, untuk perlakuan penggunaan fitohormon $A$. cepa dengan dosis $500 \mathrm{~g} / \mathrm{l}$ dan $1000 \mathrm{~g} / \mathrm{l}$ menunjukkan pertumbuhan vegetatif bibit melati putih (Jasminum sambac (L) W.Ait) memberikan pengaruh yang nyata. Pembentukan daun dimulai pada minggu ke-3 sampai minggu ke-7 dapat dilihat pada Gambar 6. Pertumbuhan jumlah daun yang semakin banyak dengan dosis yang tinggi dikarenakan fitohormon A. cepa yang mengandung senyawa allin yang berubah menjadi senyawa thiosulfinat, seperti allicin dengan bantuan enzim alliinase sebagai mana dikemukakan oleh Meutia et al (2009). 
Tabel 4. Hasil pengukuran panjang cabang menggunakan perlakuan materi setek batang dan fitohormon $A$. cepa (The results of the measurement of branch length using the treatment of stem cuttings and fitohormon A. cepa)

\begin{tabular}{cccccc}
\hline Materi Setek & \multicolumn{3}{c}{ Fitohormon A. cepa } & \multirow{2}{*}{ Total } & \multirow{2}{*}{ Rerata } \\
\cline { 2 - 4 } Batang & $\mathrm{Z}_{0}$ & $\mathrm{Z}_{1}$ & $\mathrm{Z}_{2}$ & & \\
\hline Pangkal & 18,3 & 9,9 & 8,3 & 36,5 & 12,17 \\
Tengah & 5,8 & 49,1 & 32,4 & 87,3 & 29,10 \\
Pucuk & 14 & 22,2 & 39,6 & 75,8 & 25,27 \\
\hline Total & 38,1 & 81,2 & 80,3 & 199,6 & 66,53 \\
\hline Rerata & 12,70 & 27,07 & 26,77 & 66,53 & 22,18 \\
\hline
\end{tabular}

Keterangan : $\mathrm{Z}_{0}=$ Kontrol $(0 \mathrm{~g} / \mathrm{l})$

$\mathrm{Z}_{1}=$ Fitohormon $A$. сера $500 \mathrm{~g} / 1$

$\mathrm{Z}_{2}=$ Fitohormon A. cepa $1000 \mathrm{~g} / \mathrm{l}$

Berdasarkan hasil Uji Nyata Jujur ternyata pemberian fitohormon $500 \mathrm{~g} / \mathrm{l}$ dan $1000 \mathrm{~g} / \mathrm{l}$ cukup baik untuk pertumbuhan panjang cabang. Pemberian fitohormon A. cepa sebanyak $500 \mathrm{~g} / \mathrm{l}$ dan $1000 \mathrm{~g} / \mathrm{l}$ dapat meningkatkan panjang cabang rata-rata 26,77 sampai $27,07 \mathrm{~cm}$.

Tabel 5. Hasil analisis keragaman pengaruh perlakuan materi setek batang dan fitohormon A. cepa terhadap panjang cabang (The results of the analysis of the diversity of the effect of stem cuttings and phytohormone A. cepa treatment on branch length)

\begin{tabular}{ccccccc}
\hline $\begin{array}{c}\text { Sumber } \\
\text { keragaman }\end{array}$ & DB & JK & KT & F-hitung & \multicolumn{2}{c}{ F-tabel } \\
\cline { 6 - 7 } $\begin{array}{c}\text { Petak utama } \\
\text { Kelompok }\end{array}$ & 2 & 2,65 & 1,33 & $0,56^{\text {tn }}$ & & $1 \%$ \\
$\begin{array}{c}\text { Materi setek } \\
\text { batang }\end{array}$ & 2 & 3,48 & 1,74 & $0,73^{\text {tn }}$ & 6,94 & 18 \\
Galat a & 4 & 9,49 & 2,37 & & & \\
\hline Subplot & 2 & 13,99 & 7,00 & $4,52^{*}$ & 3,88 & 6,93 \\
$\begin{array}{c}\text { A. cepa } \\
\text { Interaksi }\end{array}$ & 4 & 7,89 & 1,97 & $1,27^{\text {tn }}$ & 3,26 & 5,41 \\
Galat b & 12 & 18,58 & 1,55 & & & \\
\hline Total & \multicolumn{7}{c}{ kk a $=36,87 \%$ dan kk b $=29,78 \%$} \\
\hline
\end{tabular}

Keterangan :

tn $=$ tidak nyata

Galat $\mathrm{b}=$ perlakuan A. cepa

* = berpengaruh nyata

Pertumbuhan cabang yang lebih panjang dengan perlakuan $500 \mathrm{~g} / \mathrm{l}$ dan $1000 \mathrm{~g} / \mathrm{l}$ dikarenakan terdapat kandungan sitokinin yang dapat mendorong pemanjangan sel, sehingga akan meningkatkan tinggi tanaman $\mathrm{kk} \mathrm{a}=$ koefisien keragaman materi setek batang

Galat a = perlakuan materi setek batang

kk b = koefisien keragaman A. cepa

meningkat sebagaimana dikemukakan dalam Wicaksono et al (2016). 
Vol. 7 (3) : 1264 - 1273
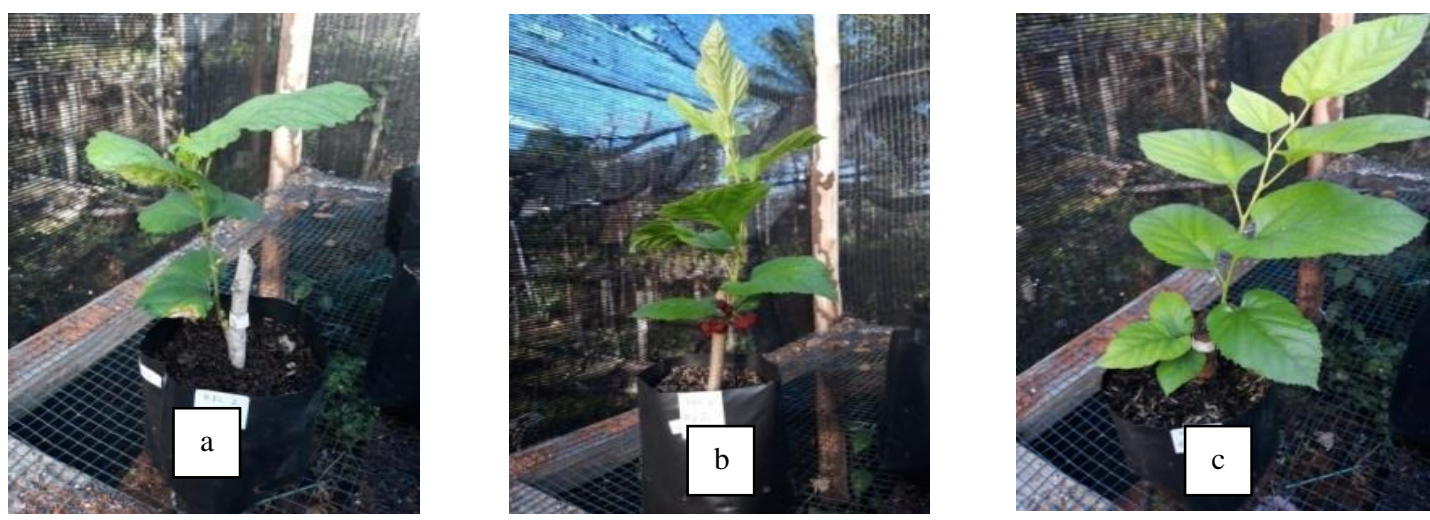

Gambar 2. Panjang cabang pada perlakuan fitohormon A. cepa $L$. (a) kontrol (0 g/l), (b) dosis $500 \mathrm{~g} / \mathrm{l},(\mathrm{c}) \mathrm{dosis} 1000 \mathrm{~g} / \mathrm{l}$ (The length of the branches in the phytohormone treatment $A$. cepa (a)control ( $0 \mathrm{~g} / \mathrm{l}),(\mathrm{b})$ dose $500 \mathrm{~g} / \mathrm{l}$, (c) dose $1000 \mathrm{~g} / \mathrm{l}$.

Jumlah Akar

Berdasarkan Tabel 6 ternyata perlakuan perlakuan materi setek batang menunjukkan pertumbuhan jumlah akar yang baik yaitu pada tengah dan pucuk. Sedangkan penggunaan fitohormon $A$. cepa ternyata dengan dosis $500 \mathrm{~g} / \mathrm{l}$, pertumbuhan jumlah akar yang lebih baik dibandingkan dengan tanpa perlakuan dan $1000 \mathrm{~g} / \mathrm{l}$. Sementara itu dari interaksi kedua perlakuan tersebut menunjukkan kombinasi materi setek batang pucuk dengan perlakuan fitohormon A. cepa dosis $500 \mathrm{~g} / \mathrm{l}$ lebih baik dibandingkan dengan kombinasi yang lainnya.

Tabel 6. Hasil pengukuran jumlah akar dengan perlakuan materi setek batang dan fitohormon $A$. cepa (The results of the measurement of the number of roots by the treatment of stem cuttings and fitohormon A. cepa).

\begin{tabular}{cccccc}
\hline \multirow{2}{*}{ Materi Setek Batang } & \multicolumn{3}{c}{ Fitohormon A. cepa } & \multirow{2}{*}{ Total } & \multirow{2}{*}{ Rerata } \\
\cline { 2 - 4 } & $\mathrm{Z}_{0}$ & $\mathrm{Z}_{1}$ & $\mathrm{Z}_{2}$ & & \\
\hline Pangkal & 7 & 4 & 2 & 13 & 4.33 \\
Tengah & 5 & 19 & 14 & 38 & 12.67 \\
Pucuk & 5 & 22 & 9 & 36 & 12.00 \\
\hline Total & 17 & 45 & 25 & 87 & 29.00 \\
\hline Rerata & 5.67 & 15 & 8.33 & 29 & 9.67 \\
\hline
\end{tabular}

Keterangan :
$\mathrm{Z}_{0}=$ Kontrol $(0 \mathrm{~g} / \mathrm{l})$
$\mathrm{Z}_{1}=$ Fitohormon $A$. cepa $500 \mathrm{~g} / \mathrm{l}$
$\mathrm{Z}_{2}=$ Fitohormon A. cepa $1000 \mathrm{~g} / 1$
Berdasarkan hasil analisis keragaman, ternyata perlakuan bagian batang yang dikombinasikan dengan zat pengatur tumbuh bawang merah menunjukkan pengaruh yang nyata terhadap jumlah daun terlihat pada Tabel 7 berikut. 
Tabel 7. Hasil analisis keragaman pengaruh perlakuan materi setek batang dan fitohormon A. cepa terhadap jumlah akar (The results of the analysis of the diversity of the effect of stem cuttings and phytohormone A. cepa treatment on the number of roots)

\begin{tabular}{|c|c|c|c|c|c|c|}
\hline \multirow{2}{*}{$\begin{array}{c}\text { Sumber } \\
\text { keragaman }\end{array}$} & \multirow{2}{*}{ DB } & \multirow{2}{*}{ JK } & \multirow{2}{*}{ KT } & \multirow{2}{*}{ F-hitung } & \multicolumn{2}{|c|}{ F-tabel } \\
\hline & & & & & $5 \%$ & $1 \%$ \\
\hline \multicolumn{7}{|l|}{ Petak utama } \\
\hline Kelompok & 2 & 1.7 & 0.85 & $1.32^{\mathrm{tn}}$ & & \\
\hline $\begin{array}{c}\text { Materi setek } \\
\text { batang }\end{array}$ & 2 & 1.84 & 0.92 & $1.43^{\text {tn }}$ & 6.94 & 18 \\
\hline Galat a & 4 & 2.58 & 0.65 & & & \\
\hline \multicolumn{7}{|l|}{ Subplot } \\
\hline A. сера & 2 & 6.42 & 3.21 & $3.88^{*}$ & 3.88 & 6.93 \\
\hline Interaksi & 4 & 3.26 & 0.82 & $0.98^{\text {tn }}$ & 3.26 & 5.41 \\
\hline Galat b & 12 & 9.94 & 0.83 & & & \\
\hline Total & & 25,74 & & $7,86 \%$ & $\mathrm{~b}=31$ & \\
\hline
\end{tabular}

Keterangan :

tn $=$ tidak nyata

Galat $\mathrm{b}=$ perlakuan $A$. cepa

* = berpengaruh nyata $\mathrm{kk} \mathrm{a}=$ koefisien keragaman materi setek batang

Galat $\mathrm{a}=$ perlakuan materi setek batang

$\mathrm{kk} \mathrm{b}=$ koefisien keragaman A. cepa

Berdasarkan hasil analisis keragaman, ternyata fitohormon A. cepa menunjukkan pengaruh yang nyata terhadap jumlah akar yaitu pada fitohormon A. cepa senilai 3,88\%. Hal ini diduga karena adanya kandungan auksin pada fitohormon A. cepa. Menurut Masitoh (2016) auksin bertindak untuk meransang

pertumbuhan akar dan vitamin B1 (thiamin) yang berperan sebagai perombakan karbohidrat menjadi energi dalam metabolism tanaman. Selain itu, Supriyanto dan Prakasa (2011) pembentukan akar pada setek tanaman dapat dipengaruhi akibat tidak seimbangnya hormon dan karbohidrat yang berperan didalam setek.
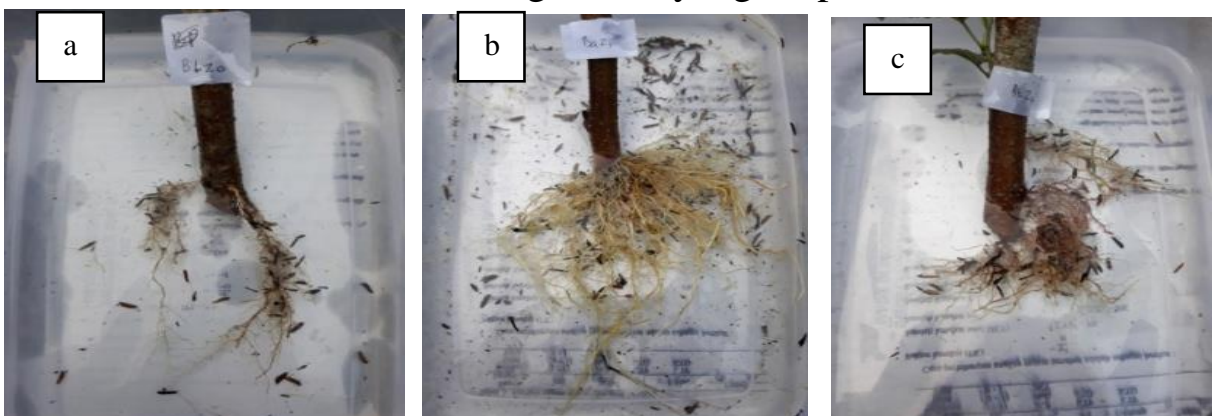

Gambar 3. Jumlah akar pada perlakuan fitohormon A. cepa (a) kontrol (0 g/l), (b) dosis $500 \mathrm{~g} / \mathrm{l}$, (c) dosis $1000 \mathrm{~g} / \mathrm{l}$ (The number of roots in the phytohormone treatment $A$. cepa (a) control $(0 \mathrm{~g}$ /l), (b) dose $500 \mathrm{~g} / \mathrm{l}$, (c) dose $1000 \mathrm{~g} / \mathrm{l}$ ) 
Jumlah Tanaman Setek yang Hidup

Berdasarkan Tabel 8 ternyata perlakuan materi setek batang menunjukkan bagian pucuk memiliki pertumbuhan yang hidup lebih baik. Sedangkan untuk perlakuan penggunaan fitohormon A. cepa dengan dosis $0 \mathrm{~g} / \mathrm{l}$ sampai $1000 \quad \mathrm{~g} / \mathrm{l}$ menunjukkan pertumbuhan yang hampir sama. Perlakuan kombinasi interaksi materi setek batang dan fitohormon A. cepa juga menunjukkan hasil yang hampir sama

Tabel 8. Hasil pengukuran jumlah tanaman setek yang hidup dengan perlakuan materi setek batang dan fitohormon $A$. cepa (The results of measurements of the number of cuttings that live by the treatment of stem cuttings and phytohormone A. cepa)

\begin{tabular}{|c|c|c|c|c|c|}
\hline \multirow{2}{*}{ Materi Setek Batang } & \multicolumn{3}{|c|}{ Fitohormon A. cepa } & \multirow{2}{*}{ Total } & \multirow{2}{*}{ Rerata } \\
\hline & $\mathrm{Z}_{0}$ & $\mathrm{Z}_{1}$ & $\mathrm{Z}_{2}$ & & \\
\hline Pangkal & 3 & 2 & 1 & 6 & 2 \\
\hline Tengah & 2 & 2 & 3 & 7 & 2.33 \\
\hline Pucuk & 2 & 3 & 3 & 8 & 2.67 \\
\hline Total & 7 & 7 & 7 & 21 & 7 \\
\hline Rerata & 2.33 & 2.33 & 2.33 & 7 & 2.33 \\
\hline
\end{tabular}

Keterangan : $\mathrm{Z}_{0}=\operatorname{Kontrol}(0 \mathrm{~g} / \mathrm{l})$

$\mathrm{Z}_{1}=$ Fitohormon $A$. cepa $500 \mathrm{~g} / 1$

$\mathrm{Z}_{2}=$ Fitohormon $A$. cepa $1000 \mathrm{~g} / \mathrm{l}$

Berdasarkan hasil analisis lebih baik digunakan untuk keragaman, ternyata perlakuan materi bagian batang yang dikombinasikan dengan fitohormon $A$. серa tidak menunjukkan pengaruh yang nyata terhadap jumlah tanaman setek yang hidup. Hal ini diduga disebabkan oleh adanya pengaruh faktor genetik dan faktor lingkungan (Darwo dan Yeni, 2018). Selain itu, media tanam arang sekam yang bersifat lebih remah mengakibatkan kemampuan serap air rendah (Agustin et al, 2014).

\section{Kesimpulan}

Penggunaan fitohormon $A$. cepa dapat digunakan untuk pertumbuhan setek batang murbei (M. multicaulis). Hasil Uji Nyata Jujur (BNJ) menunjukkan pemberian fitohormon $A$. сера sebanyak $500 \mathrm{~g} / \mathrm{l}$ sampai $1000 \mathrm{~g} / \mathrm{l}$ 


\section{DAFTAR PUSTAKA}

Agustin DA, Riniarti M, Duryat. 2014. Pemanfaatan limbah serbuk gergaji dan arang sekam sebagai media sapih untuk cempaka kuning (Michelia champaca). Jurnal Sylva Lestari. 2:49-58.

Darwo dan Yeny I. 2018. Penggunaan media, bahan stek, dan zat pengatur tumbuh terhadap keberhasilan stek masoyi (Cryptocarya massoy (Oken) Kosterm). Jurnal Penelitian Hutan Tanaman. 15:43-55.

Gaspersz V. 1991. Metoda Perancangan Percobaan. Armico. Bandung.

Isnan W dan Muin N. 2015. "Tanaman Murbei" Sumber Daya Hutan Multi-Manfaat. Info Teknis Eboni. 12:111-119.

Lesmana I, Nurdiana D, dan Siswancipto T. 2018. Pengaruh berbagai zat pengatur tumbuh alami dan asal stek batang terhadap pertumbuhan vegetatif bibit melati putih (Jasminum sambac (L.) W. Ait.). Jargos. 2:80-98.

Mangoendidjojo W. 2003. Dasar-Dasar Pemuliaan Tanaman.

Kanisius.Yogyakarta
Menteri Kehutanan. 2007. Peraturan Menteri Kehutanan No.P.35/Menhut-II/2007 tentang Hasil Hutan Bukan Kayu.

Ramadan VR, Kendarini N, dan Ashari S. 2016. Kajian pemberian zat pengatur tumbuh terhadap pertumbuhan stek tanaman buah naga (Hylocereus costaricensis). Jurnal Produksi Tanaman. 4:180186.

Masitoh S. 2016. Pengaruh Konsentrasi Ekstrak Bawang Merah Terhadap Pertumbuhan Setek Batang Buah Naga Merah (Hylocereus costaricensis (Web.) Britton \& Rose). Skripsi. Program pasca sarjana jurusan agroteknologi, Univ. Lampung, Bandar Lampung.

Supriyanto dan Prakasa KE. 2011. Pengaruh Zat Pengatur Tumbuh Rootone-F terhadap Pertumbuhan Stek Dua banga mollucana Blume . Jurnal Silvikultur Tropika. 3:5965.

Wicaksono FY, Nurmala T, Irwan AW, dan Putri ASU. 2016. Pengaruh Pemberian Gibberellin dan Sitokinin pada Konsentrasi yang Berbeda Terhadap Pertumbuhan dan Hasil Gandum (Triticum aestivum L.) Di Dataran Medium Jatinagor. J. Kultivasi. 15:53. 